IZA DP No. 8252

The Minimum Wage from a Two-Sided Perspective

Alessio J. G. Brown

Christian Merkl

Dennis J. Snower

June 2014 


\title{
The Minimum Wage from a Two-Sided Perspective
}

\author{
Alessio J. G. Brown \\ IZA and Kiel Institute for the World Economy \\ Christian Merkl \\ Friedrich-Alexander-Universität Erlangen-Nürnberg, \\ Kiel Institute for the World Economy and IZA \\ Dennis J. Snower \\ Kiel Institute for the World Economy, \\ Christian-Albrechts-Universität Kiel, IZA and CEPR
}

Discussion Paper No. 8252
June 2014

IZA

P.O. Box 7240

53072 Bonn

Germany

Phone: +49-228-3894-0

Fax: +49-228-3894-180

E-mail: iza@iza.org

Any opinions expressed here are those of the author(s) and not those of IZA. Research published in this series may include views on policy, but the institute itself takes no institutional policy positions. The IZA research network is committed to the IZA Guiding Principles of Research Integrity.

The Institute for the Study of Labor (IZA) in Bonn is a local and virtual international research center and a place of communication between science, politics and business. IZA is an independent nonprofit organization supported by Deutsche Post Foundation. The center is associated with the University of Bonn and offers a stimulating research environment through its international network, workshops and conferences, data service, project support, research visits and doctoral program. IZA engages in (i) original and internationally competitive research in all fields of labor economics, (ii) development of policy concepts, and (iii) dissemination of research results and concepts to the interested public.

IZA Discussion Papers often represent preliminary work and are circulated to encourage discussion. Citation of such a paper should account for its provisional character. A revised version may be available directly from the author. 
IZA Discussion Paper No. 8252

June 2014

\section{ABSTRACT \\ The Minimum Wage from a Two-Sided Perspective}

This paper sheds new light on the effects of the minimum wage on employment from a twosided theoretical perspective, in which firms' job offer and workers' job acceptance decisions are disentangled. Minimum wages reduce job offer incentives and increase job acceptance incentives. We show that sufficiently low minimum wages may do no harm to employment, since their job-offer disincentives are countervailed by their job-acceptance incentives.

JEL Classification: J3, J6, J2

Keywords: minimum wage, labor market, employment, unemployment, job offer, job acceptance

Corresponding author:

Christian Merkl

Friedrich-Alexander-Universität Erlangen-Nürnberg

Chair of Macroeconomics

Lange Gasse 20

90403 Nürnberg

Germany

E-mail: christian.merkl@fau.de 


\section{Introduction}

This paper provides a new theoretical explanation for the following empirical regularities: (i) Minimum wages that are "low" (close to the wage without government intervention) may have negligible or even positive employment effects. (ii) Minimum wages that are "high" have negative employment effects. ${ }^{1}$ Many theoretical explanations of the employment effects of minimum wages have focused on the demand side of the labor market, with firms' employment decisions playing the central role in determining employment (e.g. the monopsony theory of Manning 2003). Our paper provides an alternative, observationally distinct, model of how minimum wages affect employment, based on a two-sided labor market flow model which makes both firms' job offer and workers' job acceptance decisions explicit. We show analytically that larger wages depress firms' job offer rates, but raise workers' acceptance rates. Under sufficiently low minimum wages, the latter effect may dominate the former.

\section{The Model}

We use the dynamic incentive model by Brown et al. (2014) containing twosided selection in the labor market. In the context of conventional calibrations, this model fares better than the standard search and matching model in reproducing the volatilities of major labor market variables. ${ }^{2}$ Once a contact between workers and firms has been made, two types of heterogeneous matchspecific idiosyncratic shocks are revealed. Firms learn about different suitability of workers, workers learn about the disagreeability of work. Based on these idiosyncratic shocks and the exogenously given minimum wage, firms make their job offer decisions and households make their job acceptance decisions. ${ }^{3}$

We assume that the profit generated by a particular worker at a new match is subject to a match-specific random shock $\varepsilon_{t}$ in period $t$, which is meant to capture idiosyncratic variations in workers' suitability for the available jobs. The random shock $\varepsilon_{t}$ is positive and iid across workers, with a stable probability density function $G_{\varepsilon}\left(\varepsilon_{t}\right)$. Let the corresponding cumulative distribution be $J_{\varepsilon}\left(\varepsilon_{t}\right)$. In each period of analysis, a new value of $\varepsilon_{t}$ is realized for each entrant.

\footnotetext{
${ }^{1}$ These empirical regularities arise from a combination of studies. In countries where minimum wage are low (relative to the median wage), they are often found to have no negative or even positive effects on employment (e.g. Card and Krueger 1994 or Dube et al. 2010). By contrast, a minimum wage may have strong negative effects in countries where it is "high," such as in France (Abowd et al. 2000). Similar results arise for sectoral minimum wages within countries (see e.g. König and Möller 2009 for the effects of the minimum wage in the construction industry in East and West Germany).

${ }^{2}$ To focus on the contribution of this paper we make the following simplifying assumptions: separations are completely exogenous, and we do not consider aggregate uncertainty. For the precise timing assumptions in the model, see Brown et al. (2014).

${ }^{3}$ For negotiated wages (which apply when the minimum wage is not binding), the matchspecific idiosyncratic shocks are already sunk when the wage is set (for a similar assumption, see Pissarides 2009). Thus these wages do not depend on the idiosyncratic shocks.
} 
The average productivity of each worker is $a$, the wage is $w^{4}$, the unemployment benefits are $b$ and the hiring cost is $h$.

The firm maximizes the present value of its expected profit, with a time discount factor $\delta$. The profit generated by an entrant (a newly hired worker), after the random cost term $\varepsilon_{t}$ is observed, is

$$
\pi_{t}^{E}=a_{t}-\varepsilon_{t}-w_{t}-h+(1-\sigma) \delta E_{t} \pi_{t+1}^{I},
$$

where the superscript " $E$ " stands for entrant and

$$
\pi_{t+1}^{I}=a_{t+1}-w_{t+1}+\delta E_{t}(1-\sigma) \pi_{t+1}^{I},
$$

where the superscript " $I$ " stands for an incumbent worker, $\delta$ is the time discount factor and $\sigma$ is the exogenous separation rate.

The firm's "job offer incentive" (its payoff from hiring a worker) is the difference between its gross profit from hiring an entrant worker and its profit from not doing so (namely, zero):

$$
\nu_{t}^{E}=a_{t}-\varepsilon_{t}-w_{t}-h+(1-\sigma) \delta E_{t} \pi_{t+1}^{I} .
$$

The firm offers this job to a worker whenever that worker generates positive profit: $\varepsilon_{t}<\nu^{E}$. Thus, the job offer rate is

$$
\eta_{t}=J_{\varepsilon}\left(\nu_{t}^{E}\right) .
$$

The worker faces a discrete choice of whether or not to work. Her idiosyncratic disutility of work effort at a given job is $e_{t}$, a random variable, which is iid, with a stable probability density function $G_{e}\left(e_{t}\right)$. The corresponding cumulative distribution is $J_{e}\left(e_{t}\right)$. The worker's utility is linear.

The incumbent employed worker's expected present value of utility from working $\Omega_{t}^{N}\left(e_{t}\right)$ for a given work effort $e$ is

$$
\Omega_{t}^{N}=w_{t}-e_{t}+\delta E_{t}\left((1-\sigma) \Omega_{t+1}^{N}+\sigma \Omega_{t+1}^{U}\right),
$$

where $E_{t}\left(\Omega_{t+1}^{N}\right)$ is the expected present value of utility of the following period (before the realized value of the shock $e_{t+1}$ is known):

$$
\Omega_{t+1}^{N}=E_{t}\left(w_{t+1}+\delta\left((1-\sigma) \Omega_{t+2}^{N}+\sigma \Omega_{t+2}^{U}\right)\right) .
$$

The expected present value utility from unemployment is

$$
\Omega_{t}^{U}=b+\delta E_{t}\left(\mu_{t+1} \Omega_{t+1}^{N}+\left(1-\mu_{t+1}\right) \Omega_{t+1}^{U}\right),
$$

where $\mu$ is the match probability to be defined below.

An unemployed worker's expected "work incentive" $\iota_{t}$ is the expected gross difference between these two utility streams:

\footnotetext{
${ }^{4}$ The wage may be determined by bargaining or posting. For our purpose, we do not have to take a stance on the nature of the wage determination mechanism. Instead, we analyze the effects of an exogenous increase of the wage.
} 


$$
\iota_{t}=\Omega_{t}^{N}-\Omega_{t}^{U}
$$

which is

$$
\iota_{t}=w_{t}-b+\delta E_{t}\left(\left(1-\sigma-\mu_{t+1}\right) \Omega_{t+1}^{N}-\left(1-\sigma-\mu_{t+1}\right) \Omega_{t+1}^{U}\right) .
$$

The unemployed accepts a job offer when $e_{t}<\iota_{t}$. Consequently, the job acceptance rate is

$$
\alpha_{t}=J_{e}\left(\iota_{t}\right) .
$$

The change in employment is the difference between the number of hires and the number of separations. The number of hires depends the job offer probability and the job acceptance probability (contacts are assumed to be made with probability one). Thus the match probability $\left(\mu_{t}\right)$ is the product of the job offer probability $\left(\eta_{t}\right)$ and the job acceptance probability $\left(\alpha_{t}\right)$ :

$$
\mu_{t}=\eta_{t} \alpha_{t}
$$

The resulting employment dynamics equation is

$$
n_{t}=\mu_{t}+\left(1-\sigma-\mu_{t}\right) n_{t-1} .
$$

\section{Comparative Statics and Intuition}

The firm's job offer rate (Eq. 4) in the steady state is

$$
\eta=J_{\varepsilon}\left(\frac{a-w}{1-\delta(1-\sigma)}-h\right) .
$$

Differentiating with respect to the wage yields

$$
\frac{\partial \eta}{\partial w}=-\frac{1}{1-\delta(1-\sigma)} J_{\varepsilon}^{\prime}
$$

Thus, higher wages depress the job offer rate. So when a minimum wage is introduced (or rises), firms make job offers only to workers with sufficiently low idiosyncratic costs.

Analogously, the worker's job acceptance rate (Eq. 10) in steady state is

$$
\alpha=J_{e}\left(\frac{w-b}{1-\delta(1-\sigma-\mu)}\right) .
$$

Differentiation yields

$$
\frac{\partial \alpha}{\partial w}=J_{e}^{\prime} \frac{(1-\delta(1-\sigma-\mu))-(w-b) \delta\left(\frac{\partial \eta}{\partial w} \alpha\right)}{(1-\delta(1-\sigma-\mu))^{2}+(w-b) \delta \eta}
$$


This expression is positive: higher wages increase the job acceptance rate. ${ }^{5}$ The reason is that workers with a comparatively large idiosyncratic disutility shock, who were previously disinclined to accept work, are now willing to accept it because the higher wage raises the value of work relative to unemployment.

By the matching rate Eq. (11), an increase in the minimum wage accordingly has two countervailing effects, one on the job offer rate $\left(\frac{\partial \eta}{\partial w}<0\right)$ and one on the job acceptance rate $\left(\frac{\partial \alpha}{\partial w}>0\right)$ :

$$
\frac{\partial \mu}{\partial w}=\frac{\partial \eta}{\partial w} \alpha+\eta \frac{\partial \alpha}{\partial w}
$$

\section{Parametrization and Numerical Analysis}

We now analyze the effects of a minimum wage with an illustrative parametrization. For choosing steady state targets for the low wage sector, we use Blau and Robins' (1990) evidence for average offers per contact and acceptances per contact and per offer. Accordingly, we set the match probability $\mu$, which is the probability that a unemployed worker finds a new job within one period, to $12 \%$, the job offer rate to $17 \%$, and equation 11 then yields a job acceptance rate of $71 \%$. The unemployment rate $u=1-n$ is set to $8.96 \%$ (as in Cairo and Cajner 2011). According to the employment dynamics equation, we obtain an exogenous separation rate of $1.2 \%$.

Next, with reference to the empirical literature, we consider a plausible range of of labor demand elasticities $[-1,-0,25]^{6}$ and labor supply elasticities $[0.1,0.6]^{7}$. In the context of our model, we use the steady state employment equation $(n=$ $\left.\frac{\mu}{\mu+\sigma}\right)$ to calculate the labor demand and labor supply elasticities, by holding the household-side and firm-side employment activities constant, respectively.

\begin{tabular}{ccrrr}
\multicolumn{5}{c}{ Labor Demand Elasticity } \\
Labor Supply Elasticity & -0.25 & -0.5 & -0.75 & -1 \\
0.6 & $14.3 \%$ & $7.1 \%$ & - & - \\
0.5 & $14.3 \%$ & $7.1 \%$ & - & - \\
0.4 & $14.3 \%$ & $7.1 \%$ & - & - \\
0.3 & $14.3 \%$ & - & - & - \\
$\mathbf{0 . 2}$ & $14.3 \%$ & - & - & - \\
$\mathbf{0 . 1}$ & - & - & - & -
\end{tabular}

Table 1: Maximum wage increase without job losses under different labor supply and labor demand elasticities.

\footnotetext{
${ }^{5}$ The reason is that the denominator is positive, as well as the numerator (since $\frac{\partial \eta}{\partial w}<0$ ). ${ }^{6}$ See Falk and Köbel (2001) or Slaughter (2001).

${ }^{7}$ See Bargain et al. $(2011,2012)$. The latter also highlights higher labor supply responses in low-income groups.
} 
Table 1 shows the largest minimum wage that does not reduce employment, for different combinations of the labor supply and labor demand elasticities. Under the lowest labor demand elasticity $(-0.25)$, for most labor supply elasticities wage increases of up to $14.3 \%$ above the wage without government intervention are possible without job losses. This is is a similar magnitude to the minimum wage increases analyzed in Card and Krueger (1994). The number shrinks to $7.1 \%$ for a labor demand elasticity that is twice as large. Furthermore, observe that a minimum wage without job losses is only possible for a smaller range of supply elasticities.

Intuitively, a larger labor demand elasticity leads to a quantitatively stronger reaction of the job offer rate. When the job offer reaction is sufficiently large, the job acceptance effect cannot compensate for this. For lower labor demand elasticities, the job acceptance effect is dominant for small minimum wage increases. But after some moderate increase of the minimum wage, the job acceptance rate (which is calibrated to $71 \%$ ) reaches its upper bound of $100 \%$. Thus, the job acceptance effect is no longer at work and the job offer effect starts dominating. ${ }^{8}$ In other words, the labor supply elasticity does not matter any more, because further increases of the job acceptance rate are impossible. Note, however, that the quantitative response is different for wage increases below the threshold. With a labor demand elasticity of -0.25 , a wage increase of $5 \%$ leads, for example, to an employment increase of $1.8 \%, 1.5 \%$ and $1.0 \%$ with a labor supply elastsicity of $0.6,0.5$ and 0.4 respectively.

\section{Conclusion}

Our model, which disentangles household and firm decisions, complements the existing literature by outlining a mechanism that is absent in standard search and matching models. We show analytically that larger wages depress firms' job offer rates, but raise workers' acceptance rates. Under moderate minimum wages, the latter effect may dominate the former. Obviously, there are other channels that prevent negative effects of a moderate minimum wage (e.g. monopsony power). However, our numerical analysis illustrates that our job acceptance effect alone is quantitatively meaningful. It is certainly of interest for future research to combine different theoretical effects and to disentangle the job offer and job acceptance effects in labor market data.

\section{References}

[1] Abowd, John, Kramarz, Francis, Margolis, David and Thomas Philippon (2000), The Tail of Two Countries: Minimum Wages and Employment in France and the United States, IZA Discussion Paper, IZA Discussion Paper 203.

\footnotetext{
${ }^{8}$ For a given labor demand elasticity, the largest mimimum wage that does not reduce employment is the same for several different labor supply elasticities. At the threshold, the job acceptance rate has hit its upper bound.
} 
[2] Bargain, Olivier, Orsini, Kristian and Andreas Peichl (2012), Comparing Labor Supply Elasticities in Europe and the US: New Results, IZA Discussion Paper 6735.

[3] Bargain, Olivier, Orsini, Kristian and Andreas Peichl (2011), Labor Supply Elasticities in Europe and the US, IZA Discussion Paper 5820.

[4] Blau, David M. and Philip K. Robins (1990), Job Search Outcomes for the Employed and Unemployed, Journal of Political Economy, 98, 637-655.

[5] Brown, Alessio J. G., Merkl, Christian and Dennis J. Snower (2014), An Incentive Theory of Matching, Macroeconomic Dynamics, forthcoming.

[6] Card, David and Alan B. Krueger (1994), Minimum Wages and Employment: A Case Study of the Fast-Food Industry in New Jersey and Pennsylvania, American Economic Review, 84, 772-793.

[7] Cairo, Isabel and Tomaz Cajner (2011), Human Capital and Unemployment Dynamics, SED Meeting Papers, No 1145.

[8] Dube, Arindrajit, Lester, William T. and Michael Reich (2010), Minimum Wage Effects Across State Borders: Estimates Using Contiguous Countries, The Review of Economics and Statistics, 92, 945-964.

[9] Falk, Martin and Bertrand Köbel (2001), A Dynamic Heterogeneous Labour Demand Model for German Manufacturing, Applied Economics, $33,339-348$.

[10] König, Mario and Joachim Möller (2009), Impacts of Minimum Wages: A Microdata Analysis for the German Construction Sector, International Journal of Manpower, 30, 716-741.

[11] Manning, Alan (2003), Monopsony in Motion: Imperfect Competition in Labor Markets, Princeton University Press.

[12] Pissarides, Christopher A. (2009), The Unemployment Volatility Puzzle: Is Wage Stickiness the Answer?, Econometrica, 77, 1339-1369.

[13] Slaughter, Matthew (2001), International Trade and Labor-Demand Elasticities, Journal of International Economics, 54, 27-56. 


\section{Appendix: Analytical Derivations}

\subsection{Differentiation of the Job Acceptance Rate with Re- spect to the Wage}

Derivation of Equation 16:

Differentiating the employment incentive with respect to the wage yields

$$
\frac{\partial \iota}{\partial w}=\frac{(1-\delta(1-\sigma-\mu))-(w-b) \delta \frac{\partial \mu}{\partial w}}{(1-\delta(1-\sigma-\mu))^{2}},
$$

given that

$$
\frac{\partial \mu}{\partial w}=\frac{\partial \eta}{\partial w} \alpha+\eta \frac{\partial \alpha}{\partial w},
$$

this yields

$$
\frac{\partial \iota}{\partial w}=\frac{(1-\delta(1-\sigma-\mu))-(w-b) \delta\left(\frac{\partial \eta}{\partial w} \alpha+\eta \frac{\partial \alpha}{\partial w}\right)}{(1-\delta(1-\sigma-\mu))^{2}} .
$$

Thus,

$$
\begin{gathered}
\frac{\partial \alpha}{\partial w}=J_{e}^{\prime} \frac{\partial \iota}{\partial w}=J_{e}^{\prime} \frac{(1-\delta(1-\sigma-\mu))-(w-b) \delta\left(\frac{\partial \eta}{\partial w} \alpha+\eta \frac{\partial \alpha}{\partial w}\right)}{(1-\delta(1-\sigma-\mu))^{2}} \\
\frac{\partial \alpha}{\partial w}\left(1+\frac{(w-b) \delta \eta}{(1-\delta(1-\sigma-\mu))^{2}}\right)=J_{e}^{\prime} \frac{(1-\delta(1-\sigma-\mu))-(w-b) \delta\left(\frac{\partial \eta}{\partial w} \alpha\right)}{(1-\delta(1-\sigma-\mu))^{2}} \\
\frac{\partial \alpha}{\partial w}=J_{e}^{\prime} \frac{(1-\delta(1-\sigma-\mu))-(w-b) \delta\left(\frac{\partial \eta}{\partial w} \alpha\right)}{(1-\delta(1-\sigma-\mu))^{2}} \\
=J_{e}^{\prime} \frac{(1-\delta(1-\sigma-b)}{(1-\delta(1-\sigma-\mu))^{2}} \\
(1-\delta(1-\sigma-\mu))-(w-b) \delta\left(\frac{\partial \eta}{\partial w} \alpha\right)
\end{gathered}
$$




\subsection{Calculation of Elasticities in the Parametrization and Numerical Analysis}

$$
\begin{aligned}
\frac{\partial n}{\partial w} \frac{w}{n} & =\frac{\partial \frac{\mu}{\mu+\sigma}}{\partial w} \frac{w}{n}=\frac{\partial \frac{\eta \alpha}{\alpha \eta+\sigma}}{\partial w} \frac{w}{n} \\
& =\frac{\left(\frac{\partial \eta}{\partial w} \alpha+\frac{\partial \alpha}{\partial w} \eta\right)(\mu+\sigma)-\mu\left(\frac{\partial \eta}{\partial w} \alpha+\frac{\partial \alpha}{\partial w} \eta\right)}{(\mu+\sigma)^{2}} \frac{w}{n} \\
& =\frac{\left(\frac{\partial \eta}{\partial w} \alpha+\frac{\partial \alpha}{\partial w} \eta\right) \sigma}{(\mu+\sigma)^{2}} \frac{w}{n}
\end{aligned}
$$

For e.g. deriving the labor demand elasticity, we keep the household side constant, i.e. $\frac{\partial \alpha}{\partial w}=0$. Thus:

$$
\begin{aligned}
\frac{\partial n}{\partial w} \frac{w}{n} & =\frac{\frac{\partial \eta}{\partial w} \alpha \sigma}{(\mu+\sigma)^{2}} \frac{w}{n} \\
& =\frac{\frac{\partial \eta}{\partial w} \alpha \sigma}{(\mu+\sigma)} \frac{w}{\mu} \\
& =\frac{\frac{\partial \eta}{\partial w} \sigma}{(\mu+\sigma)} \frac{w}{\eta} \\
& =\frac{\partial \eta}{\partial w} \frac{w}{\eta} u
\end{aligned}
$$

